\title{
Irrigação e fertirrigação no desenvolvimento de eucalipto
}

\author{
Irrigation and fertirrigation in the Eucalyptus development
}

\author{
Vitor Gabriel Marinho de Faria Pereira', Adriano da Silva Lopes"I, Isabela Braga \\ Belchior ${ }^{\mathrm{III}}$, Eder Duarte Fanaya Júnior ${ }^{\mathrm{IV}}$, Arthur Pacheco ${ }^{\mathrm{v}}$, Kelvin Rosalvo Melgar \\ Brito $^{\mathrm{VI}}$
}

\section{Resumo}

O objetivo do trabalho foi avaliar a influência da irrigação localizada e da fertirrigação sobre o desenvolvimento do híbrido de eucalipto Grancam, no quarto ano após a sua implantação. O delineamento experimental foi em blocos casualizados, com parcelas subdivididas. As parcelas foram dois sistemas de irrigação localizada (microaspersão e gotejamento) e um tratamento sem irrigação e, as subparcelas, a adubação convencional e a fertirrigação. Foram avaliados: altura de plantas, diâmetro a altura do peito e volume de madeira. Os resultados foram submetidos à análise de variância e teste Tukey a $5 \%$ de significância. A altura das plantas foi $13 \%$ maior no sistema gotejamento e $11 \%$ no sistema de microaspersão em relação à área sem irrigação. A irrigação promoveu maiores valores de diâmetro a altura do peito, resultando em aumento de $19,8 \%$ na produção volumétrica de madeira quando irrigada por microaspersão e 17,7\% quando irrigada por gotejamento, em relação à área sem irrigação. A irrigação localizada aumenta a produção volumétrica de madeira para o híbrido Grancam, além disso, quando utilizada a irrigação por gotejamento, há aumento da eficiência do uso da água na produção volumétrica de madeira. A fertirrigação pode substituir a adubação convencional em florestas irrigadas.

Palavras-chave: Grancam; Irrigação localizada; Manejo florestal; Volume de madeira

\begin{abstract}
The objective of this study was to evaluate the influence of in-ground irrigation and fertirrigation on the development of hybrid eucalyptus Grancam, in the fourth year after its implementation. The experimental design was a randomized block with split plots. The plots were two trickle irrigation systems (drip and micro sprinkler) and no irrigation treatment and the subplots, the conventional fertilization and fertirrigation. It was evaluated: plant height, diameter at breast height and wood volume. The results were submitted to analysis of variance and Tukey test at $5 \%$ of significance. The plant height was $13 \%$ higher in the drip irrigation and $11 \%$ in system micro-sprinkler system, in relation the area without irrigation. The Irrigation showed higher values of diameter at breast height, resulting in a $19.8 \%$ increase in the volume production of wood when irrigated by micro and $17.7 \%$ when irrigated by drip over the area without irrigation. The irrigation increases volumetric timber production. The drip irrigation increases the efficiency of water use in volume production of wood. The fertirrigation can replace conventional fertilization in irrigated forests.
\end{abstract}

Keywords: Grancam; In-ground irrigation; Management forest; Volume of wood

\footnotetext{
Engenheiro Florestal, MSc., Universidade Estadual de Mato Grosso do Sul, Rod. Graziela Maciel Barroso, km 12, CEP 79200-000, Aquidauana (MS), Brasil. vitor_gmfp@hotmail.com (ORCID: 0000-0001-8374-2058)

Engenheiro Agrônomo, Dr., Professor do Programa de Pós-Graduação em Agronomia - Produção Vegetal, Universidade Estadual de Mato Grosso do Sul, Rod. Graziela Maciel Barroso, km 12, CEP 79200-000, Aquidauana (MS), Brasil. lopes@uems.br (ORCID: 0000-0003-2211-6576)

III Engenheira Florestal, MSc., Doutoranda em Engenharia Florestal, Universidade Federal de Lavras, Av. Doutor Sylvio Menicucci, Aquenta Sol, CEP 37200-000, Lavras (MG), Brasil. isabela_bbelchior@hotmail.com (ORCID: 0000-0003-4071-3323)

IV Engenheiro Agrônomo, Dr., Pós Doutorando em Agronomia, Universidade Estadual de Mato Grosso do Sul, Rod. Graziela Maciel Barroso, km 12, CEP 79200-000, Aquidauana (MS), Brasil. eder.fanayajr@alumni.usp.br (ORCID: 0000-0002-2292-6504)

Engenheiro Agrônomo, Dr., Universidade Estadual de Mato Grosso do Sul, Rod. Graziela Maciel Barroso, km 12, CEP 79200-000, Aquidauana (MS), Brasil. arthur_ap@hotmail.com (ORCID: 0000-0001-8387-3461).

vi Engenheiro Florestal, MSc., Doutorando em Agronomia, Universidade Estadual de Mato Grosso do Sul, Rod. Graziela Maciel Barroso, km 12, CEP 79200-000, Aquidauana (MS), Brasil. kelvin_rosalvo@hotmail.com (ORCID: 0000-0002-0687-6017)
} 


\section{Introdução}

Estimam-se que em 2013 foram aportados cerca de 70 a 80 bilhões dólares em ativos florestais. A China, Índia e os Estados Unidos juntos possuem $61 \%$ da área mundial de floresta plantada, mas, representam apenas $22 \%$ das florestas destinadas à exploração comercial (INDÚSTRIA BRASILEIRA DE ÁRVORES, 2014). Em contrapartida, o Brasil, com 7,75 milhões de hectares de florestas plantadas, representa $17 \%$ da madeira colhida mundialmente (INDÚSTRIA BRASILEIRA DE ÁRVORES, 2015). Resultado da adaptabilidade, elevada taxa de crescimento e plasticidade a diferentes condições de clima e solo, em diferentes regiões do país (PAULA et al., 2012).

Para o Eucalyptus, a possibilidade de realização do cruzamento entre espécies pode reunir características de diferentes espécies em uma planta, denominado hibridação. $O$ resultado da hibridação do Eucalyptus grandis com o Eucalyptus camaldulensis é o híbrido de eucalipto Grancam, que apresenta características de rápido crescimento e boa qualidade da madeira presente em Eucalyptus grandis (CONSELHO DE INFORMAÇÕES SOBRE BIOTECNOLOGIA, 2008), e a boa adaptabilidade à deficiência hídrica e nutricional de solos, do Eucalyptus camaldulensis (FONSECA et al., 2010), pois, cada espécie de Eucalyptus se adapta de maneiras distintas em condições e ambientes diferentes (PEREIRA et al., 2000).

Nesse sentido, mesmo com a genética de boa adaptabilidade do Eucalyptus camaldulensis à restrição hídrica, a disponibilidade hídrica torna-se um importante fator para o eucalipto Grancam, visto que estimula a atividade do meristema cambial do Eucalyptus grandis, resultando em formação de lenho (FREITAS et al., 2015). Sabe-se que a água é um dos principais constituintes do tecido vegetal, responsável por garantir a eficácia dos processos como translocação de solutos e abertura e fechamento de estômatos, sendo que sua indisponibilidade pode causar danos ao metabolismo da planta (TAIZ; ZEYGER, 2009).

Consequentemente, a falta de água minimiza a produção de madeira, uma vez que o estresse hídrico diminui a taxa de fotossíntese, transpiração e condutância estomática (DOMBROSKI et al., 2014). Segundo Valadares, Paula e Paula (2014), na ausência do fornecimento adequado de água, a perda de turgescência estimula o fechamento dos estômatos, reduzindo a transpiração. Assim, a disponibilidade hídrica torna-se um dos principais recursos que garantem um bom desenvolvimento das culturas florestais.

Sanar o deficit hídrico é garantir um melhor desenvolvimento das florestas de eucalipto. Nesse sentido, tecnologias como a irrigação promovem água às culturas conforme sua necessidade (SOUZA et al., 2004). Aliada a irrigação, a fertirrigação é uma tecnologia que pode ser empregada no setor florestal visando à aplicação de fertilizantes via água de irrigação (BORGES et al., 2006). Realizar a adubação, aliada à irrigação, pode potencializar o crescimento das culturas florestais, visto que a fertirrigação aumenta a condução dos nutrientes às raízes.

Alguns autores evidenciaram os efeitos da irrigação e fertirrigação em espécies de Eucalyptus. Lopes et al. (2007), avaliando o efeito de diferentes lâminas de irrigação em plantas de Eucalyptus grandis, observaram que as maiores lâminas de irrigação diárias, proporcionaram os maiores acúmulos de nutrientes nas plantas. Nesse contexto, evidencia-se que provavelmente este gênero realiza maior absorção de nutrientes, quando submetido à irrigação.

Por outro lado, Pacheco et al. (2016) em Aquidauana-MS, avaliando o efeito da irrigação localizada e da fertirrigação na cultura do eucalipto Grancam, no terceiro ano após implantação, constataram que houve maior crescimento em altura de plantas, diâmetro a altura do peito e volume de madeira para áreas irrigadas quando comparadas as áreas sem irrigação. Assim, evidencia-se que o uso da irrigação localizada aumenta a produtividade florestal em espécies de eucalipto.

De acordo com Fernandes, Thaila e Faria (2012) há efeitos da irrigação e nutrição mineral no crescimento de eucalipto, nos cincos anos iniciais, e que as áreas irrigadas proporcionaram maiores valores biométricos e maiores incrementos, quando comparado a áreas sem irrigação.

Atualmente, poucos estudos foram realizados em relação ao desenvolvimento do híbrido de eucalipto Grancam irrigado a campo, mesmo sabendo que fatores como irrigação e fertirrigação podem 
influenciar na produtividade florestal. Assim, o presente estudo buscou avaliar a influência da irrigação localizada e da fertirrigação sobre o desenvolvimento do híbrido de eucalipto Grancam, durante o quarto ano após sua implantação, em Aquidauana-MS.

\section{Material e métodos}

O trabalho foi realizado na área experimental da Universidade Estadual de Mato Grosso do Sul (UEMS), em Aquidauana-MS, com coordenadas geográficas $20^{\circ} 27^{\prime} 08^{\prime}$ 'Sul, $55^{\circ} 40^{\prime} 15^{\prime \prime}$ Oeste e altitude média de 191 metros.

Segundo a classificação de Köppen, o clima da região é descrito como clima tropical quente subúmido, com precipitação média anual (Precipitação média calculada a partir dos dados do ano de 2007 a 2015, obtida em: http://www.inmet.gov.br/portal/index.php?r=estacoes/estacoesautomaticas) de $1286 \mathrm{~mm}$. O solo do local do experimento foi classificado, segundo Schiavo et al. (2010), como Argissolo Vermelho distrófico de textura arenosa.

Por meio da estação meteorológica instalada na unidade universitária de Aquidauana foram obtidos dados climáticos diários de umidade relativa do ar, radiação solar global, temperatura máxima e mínima e velocidade do vento, entre o período avaliado, $42^{\circ}$ mês após plantio (MAP), referente a outubro/2014, e 53 MAP, referente a setembro/2015 (Figura 1).

Figura 1 - Pluviosidade e temperatura (média, máxima e mínima) no município de Aquidauana-MS, entre outubro de 2014 (42을 $\mathrm{MAP})$ e setembro de 2015 (53 $\left.{ }^{\circ} \mathrm{MAP}\right)$.

Figure 1 - Rainfall and temperature (average, maximum and minimum) in the municipality of

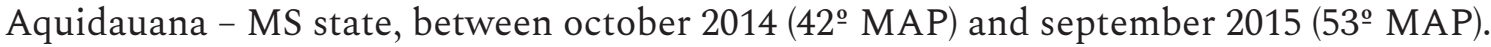

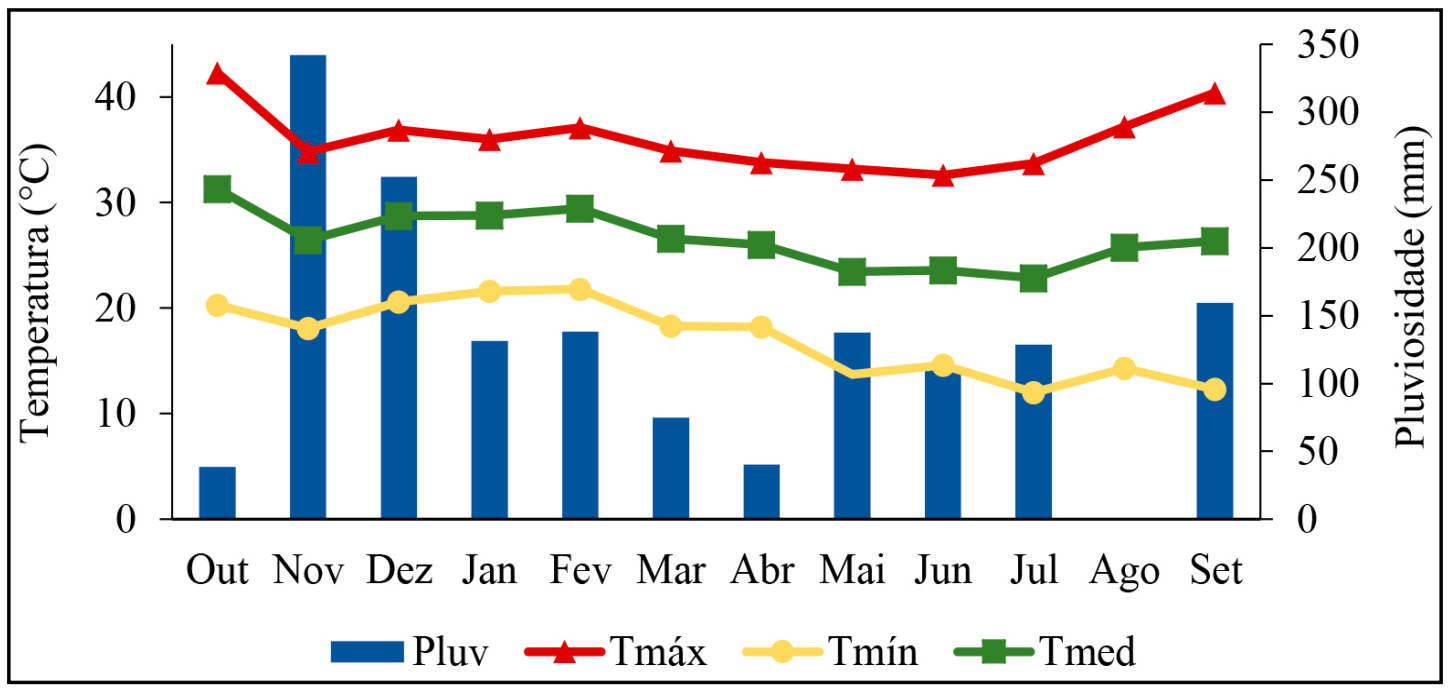

Fonte: Autores (2019)

O híbrido utilizado foi o Grancam, clone 1277 (Eucalyptus grandis x Eucalyptus camaldulensis). O plantio foi realizado em 19 de abril de 2011, utilizando mudas adquiridas comercialmente, com espaçamento de 2,25 m entre plantas e $4 \mathrm{~m}$ entre linhas, cuja adubação foi realizada a partir da análise química do solo.

Antes da implantação do experimento, a área era vegetada por pastagem, assim, antes do plantio foi realizado a gradagem e o controle de plantas invasoras, sendo estas dessecadas com a aplicação na dosagem de $4 \mathrm{~L} \mathrm{ha}^{-1}$ do produto comercial do herbicida Glyphosate contendo 360 g i.a. $\mathrm{L}^{-1}$.

O experimento foi implantado em blocos casualizados, com parcelas subdivididas, utilizando- 
se quatro blocos e duas replicações dentro de cada bloco, e os tratamentos empregados nas parcelas corresponderam a dois sistemas de irrigação localizada (microaspersão e gotejamento) e um tratamento sem irrigação. As subparcelas foram a adubação convencional e a fertirrigação, em que cada subparcela consistia em 10 plantas, totalizando 24 subparcelas.

No sistema de irrigação por gotejamento (GOT) foram utilizados gotejadores autocompensantes, com vazão de $2,4 \mathrm{~L} \mathrm{~h}^{-1}$ e espaçamento de $0,5 \mathrm{~m}$ entre emissores, com pressão de serviço de 10 m.c.a. No sistema de irrigação por microaspersão (MIC) foram utilizados microaspersores com vazão unitária de $48 \mathrm{~L} \mathrm{~h}^{-1}$, raio de alcance de 1,5 m e pressão de serviço de 40 m.c.a, instalado um emissor por planta a uma distância de $30 \mathrm{~cm}$.

O manejo da irrigação foi baseado na estimativa da evapotranspiração de referência (ETo) a partir da Equação de Penman-Monteith (ALLEN et al., 1998). A evapotranspiração da cultura (ETc) foi estimada de acordo com Bernardo et al. (2006). O coeficiente de cultura utilizado para eucalipto foi de 0,82 (ALVES et al., 2013). A irrigação foi realizada quando o somatório da evapotranspiração da cultura era igual ou superior a $9 \mathrm{~mm}$.

A precipitação total entre a implantação (abril/2011) e o último período avaliado (53 $\mathrm{MAP}$ ) foi de 5974,04 mm. A lâmina de irrigação (LI) foi de 1655,12 mm para MIC e 1081,57 mm para GOT, resultando em uma lâmina total (LT) de 7629,16 mm para MIC e 7055,61 para GOT.

No plantio das mudas de eucalipto, a adubação foi realizada com base na análise química do solo e de acordo com as indicações de Andrade (2004), no qual a adubação nitrogenada, fosfatada e potássica foi obtida com o formulado 04-20-20, incorporado ao solo na quantia de $115 \mathrm{~g}$ por planta. Foram realizados dois manejos de adubação, uma adubação por meio da fertirrigação (FERT) e outro por meio da adubação convencional (ADUB) em tratamentos irrigados por microaspersão e gotejamento e para o tratamento não irrigados (AD-SI) no $21^{\circ} \mathrm{MAP}$.

A adubação de cobertura convencional foi realizada abrindo sulcos em semicírculos, e na FERT os adubos foram diluídos em água e aplicado pelo sistema de injeção de fertilizantes do tipo Venturi. As doses utilizadas seguiram as recomendações de Gonçalves et al. (2008), $40 \mathrm{~kg} \mathrm{ha}^{-1}$ de nitrogênio (N), $20 \mathrm{~kg}$ $\mathrm{ha}^{-1}$ de potássio (K) e 3,3 $\mathrm{kg} \mathrm{ha}^{-1}$ de boro (B). Repetiu-se a adubação potássica no $32^{\circ}$ MAP.

Os atributos avaliados foram altura de plantas (ALT) por meio do uso de clinômetro digital, diâmetro a altura do peito (DAP) e o volume de madeira (VOL), utilizando a Equação 1. O período de avaliação foi entre o $42^{\circ}$ MAP (01 de outubro de 2014) e o 53ํㅡㄹ $\mathrm{MAP}$ (30 de setembro de 2015).

$$
\mathrm{VOL}=\mathrm{A}_{\mathrm{DAP}} \operatorname{ALT} 0,5 \mathrm{DP}
$$

em que:

VOL - volume de madeira, $\mathrm{m}^{3} \mathrm{ha}^{-1}$

$\mathrm{A}_{\mathrm{DAP}}$ - área do caule a altura do peito, $\mathrm{m}^{2}$

ALT - altura de planta, $m$

0,5 - fator de forma de eucalipto (VILAS BÔAS; MAX; MELO, 2009)

DP - densidade populacional, plantas ha ${ }^{-1}$

Para o cálculo da eficiência do uso da água na produção de madeira, foi utilizada a Equação 2, adaptada de Rötzer et al. (2017).

$$
\mathrm{C}=\frac{\mathrm{LT}}{\mathrm{VOL}}
$$

em que:

$\mathrm{C}$ - volume de água para produção de $1 \mathrm{~m}^{3}$ de madeira, $\mathrm{mm} \mathrm{m}^{-3}$

LT - quantidade total de água (lâmina de irrigação + precipitação), mm

VOL - volume de madeira, $\mathrm{m}^{3} \mathrm{ha}^{-1}$

Foi realizada uma análise do comportamento florestal, por meio do incremento, definido como 
o crescimento da árvore em um determinado período, calculando assim o incremento corrente (IC), conforme Equação 3, e o incremento médio (IM) (Equação 4) para o período analisado ( $42^{\circ}$ ao $53^{\circ}$ MAP).

$$
\begin{aligned}
& \mathrm{IC}_{\mathrm{t}}=\text { var }_{\mathrm{t}}-\text { var }_{\mathrm{t}-1} \\
& \mathrm{IM}_{\mathrm{t}}=\frac{\mathrm{var}_{\mathrm{t}}}{\mathrm{Idade}_{\mathrm{t}}} \\
& \text { em que: } \\
& \mathrm{ICt}-\text { incremento corrente no período } \mathrm{t} \\
& \mathrm{var}_{\mathrm{t}}-\text { variável dendrométrica no período } \mathrm{t} \\
& \mathrm{var}_{\mathrm{t}-1}-\text { variável dendrométrica no período } \mathrm{t}-1 \\
& \mathrm{IM}^{-} \text {incremento corrente no período } \mathrm{t} \\
& \mathrm{Idade}_{\mathrm{t}}-\text { idade do povoamento no período } \mathrm{t}
\end{aligned}
$$

Os resultados foram submetidos à análise de variância e, para aqueles que mostraram efeito significativo dos tratamentos pelo teste $\mathrm{F}$, procedeu-se o teste de Tukey a $5 \%$ de significância para comparações de médias.

\section{Resultados e discussão}

A precipitação no período avaliado foi de $1554 \mathrm{~mm}$, correspondendo a um acréscimo de 20,8\% em relação à média anual (Figura 1). A lâmina de irrigação (LI) para o sistema de microaspersão foi de 127,2 mm e 108,0 mm para o sistema de gotejamento. A lâmina de irrigação no sistema de microaspersão foi 15,1\% maior que no sistema de gotejamento (Tabela 1), possivelmente reflexo da melhor eficiência na aplicação da água realizada pelo sistema de gotejamento (BERNARDO; SOARES; MANTOVANI, 2006), minimizando perdas por deriva e /ou evaporação.

Tabela 1 - Estimativa da evapotranspiração do híbrido de eucalipto Grancam para irrigação localizada $\left(\mathrm{ETc}_{\mathrm{Loc}}\right)$, com valores de máxima, mínima, média e acumulada, lâmina de irrigação (LI) e lâmina total

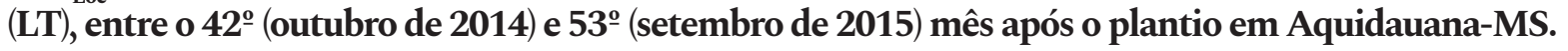

Table 1 - Estimate evapotranspiration of hybrid eucalyptus Grancam for in-ground irrigation (ETc $\mathrm{Lcc}_{\text {Loc }}$, with values of maximum, minimum, average and accumulated, irrigation blade (LI) and the total blade (LT) between $42^{\circ}$ (October 2014) and 53 (September 2015) month after planting in Aquidauana, MS state.

\begin{tabular}{cccc|ccc}
\hline & \multicolumn{9}{c}{ ETc $_{\text {Loc }}$} & & LI & LT $^{*}$ \\
\cline { 2 - 6 } & Máxima & $\begin{array}{r}\text { Mínima } \\
\text { mm dia }\end{array}$ & Média & Acumulada & & \\
\hline SI & - & - & - & - & - & 1554,15 \\
MIC & 5,19 & 0,65 & 2,84 & 1034,35 & 127,2 & 1681,35 \\
GOT & 4,22 & 0,53 & 2,31 & 842,04 & 108,0 & 1662,15 \\
\hline
\end{tabular}

Em que: *LT = LI + precipitação; SI - Área sem irrigação; GOT - sistema de irrigação por gotejamento; MIC - sistema de irrigação por microaspersão.

Osvalores de lâminas totais $(\mathrm{LT})(\mathrm{LT}=\mathrm{LI}+$ precipitação) foram de 1681,35 mm para microaspersão, 
1662,15 mm para sistema de gotejamento e 1554,15 mm para área sem irrigação. O sistema de microaspersão proporcionou uma lâmina total $1,1 \%$ a mais que o sistema de gotejamento e 7,6\% a mais que a área sem irrigação. Já, o sistema de gotejamento obteve lâmina total 6,5\% a mais que a área sem irrigação (Tabela 1). Os meses de outubro, março, abril e agosto apresentaram precipitação acumulada menor que $100 \mathrm{~mm}$. Logo, os meses de novembro e dezembro apresentaram índice pluviômetro acima dos $250 \mathrm{~mm}$ mensais (Figura 1).

Em relação as estimativas da evapotranspiração da cultura para irrigação localizada $\left(E T c_{\text {Loc }}\right)$, o sistema de microaspersão obteve $\mathrm{ETc}_{\text {Loc }}$ acumulada de $1034,35 \mathrm{~mm}$ e o sistema de gotejamento de 842,04 $\mathrm{mm}$, sendo a $\mathrm{ETc}_{\mathrm{Loc}}$ acumulada no sistema de microaspersão 18,6\% maior que no sistema de gotejamento (Tabela 1). Este fato pode ser explicado devido ao sistema de gotejamento apresentar alta eficiência de aplicação de água, utilizando um menor volume em relação aos sistemas de aspersão (MAROUELLI; SILVA; SILVA, 2012), minimizando assim a perda de água por evaporação e deriva.

Os fatores analisados (sistemas de irrigação x adubação) não apresentaram interação significativa. Os sistemas de irrigação localizada (MIC e GOT) proporcionaram valores superiores para a altura de plantas, quando comparadas à área sem irrigação (SI). Os sistemas de microaspersão e gotejamento, diferiram estatisticamente da área sem irrigação, em que as plantas irrigadas cresceram para GOT 13\% e MIC $11 \%$ a mais em relação a SI, no $53^{\circ}$ MAP (Tabela 2).

Neste contexto, o manejo da umidade no solo por meio da irrigação localizada, proporcionou maior crescimento em altura. A irrigação evitou possíveis distúrbios metabólicos nas plantas causados pela falta de água, e potencializou o seu desenvolvimento. Corroborando Fernandes, Thaila e Faria (2012) que analisaram o crescimento de florestas de eucalipto submetidas à irrigação e constataram que áreas irrigadas cresceram mais em altura, em relação às áreas não irrigadas.

Observa-se claramente que a água é um recurso-chave e limitante de produtividade, sendo constantemente perdida no processo fotossintético para atmosfera e necessita ser reposta pelo ambiente (TAIZ; ZEIGER, 2009) ou por meio do uso da tecnologia de irrigação.

Em relação ao DAP, a irrigação proporcionou maiores resultados no início do período avaliado $\left(42^{\circ}\right.$ MAP). Os sistemas de microaspersão, gotejamento e área sem irrigação não diferiram estatisticamente após o $50^{\circ}$ MAP (Tabela 2).

Possivelmente o aumento do incremento em DAP da área sem irrigação, após o $50^{\circ} \mathrm{MAP}$, seja reflexo da elevação do índice pluviométrico nos meses de novembro e dezembro (Figura 1), que refletiu no aumento do incremento para a área sem irrigação e minimizou o uso da irrigação nos outros sistemas. Neste sentido, Fernandes, Thaila e Faria (2012), verificaram proximidade dos valores de DAP entre tratamentos irrigados e não irrigados, reflexo de anos mais chuvosos que a média normal de sua região.

Aliado a isto, provavelmente a minimização do incremento em DAP para tratamentos irrigados pode estar associada à competição entre espécies de eucalipto, visto que, o eucalipto irrigado obteve maiores médias de diâmetro em menor tempo e antecipando a competição intraespecífica, quando comparado à área sem irrigação (Figuras 2,3 e 4).

Este fato pode ser melhor compreendido conforme a análise do comportamento florestal pelo método de maximização da produção anual. Deste modo, por meio dos gráficos de produção pode-se determinar o melhor manejo a ser adotado (RODRIGUES, 1991).

Observa-se que nos gráficos de incremento corrente (IC) e incremento médio (IM) no período avaliado, para diâmetro a altura do peito, as curvas de incremento corrente e incremento médio tendem a se cruzar nos sistemas irrigados antes do sistema sem irrigação (Figura 2).

Nesse sentido, Souza et al. (2006) observaram que o aumento da disponibilidade hídrica reflete em aumento de incremento médio. Já, Fernandes, Thaila e Faria (2012) observaram que a irrigação proporcionou maiores valores de incremento médio anual, quando comparadas a não irrigadas. Portanto, a irrigação proporciona maiores valores de DAP em menor tempo.

Em contrapartida, para o atributo altura de plantas, o incremento corrente e incremento médio nos gráficos de produção apresentaram pouca diferença em seu comportamento (Figura 3). Esse fator pode ser explicado, porque a altura de plantas de eucalipto é pouco influenciada pelo adensamento de plantas (espaçamento), ou seja, a competição intraespecífica reflete grande parte no desenvolvimento do 
DAP e pouco na altura de plantas, variando de acordo com a influência de parâmetros como a qualidade do sítio, idade de avaliação (OLIVEIRA NETO et al., 2010) e espaçamento entre plantas.

Tabela 2 - Comparação de médias entre os sistemas de irrigação utilizados no cultivo do híbrido de eucalipto Grancam para altura de plantas (ALT) e diâmetro a altura do peito (DAP), em Aquidauana-MS.

Table 2 - Comparison of means between the irrigation systems used in the grow of hybrid eucalyptus Grancam for height of plant (ALT) and diameter at breast height (DBH), in Aquidauana, MS state.

\begin{tabular}{|c|c|c|c|c|c|}
\hline \multirow{3}{*}{ MAP } & \multicolumn{5}{|c|}{ Tratamentos } \\
\hline & MIC & GOT & SI & DMS & CV $(\%)$ \\
\hline & ALT & & & & \\
\hline & \multicolumn{4}{|c|}{$\mathrm{m}$} & \\
\hline 42 & $17,61 \mathrm{a}$ & $17,39 \mathrm{a}$ & $15,81 \mathrm{~b}$ & 1,54 & 7,19 \\
\hline 45 & $18,64 \mathrm{a}$ & $18,86 \mathrm{a}$ & $16,91 \mathrm{~b}$ & 1,56 & 6,81 \\
\hline 50 & 20,38 a & $20,78 \mathrm{a}$ & $18,11 \mathrm{~b}$ & 1,55 & 6,21 \\
\hline \multirow[t]{3}{*}{53} & $20,81 \mathrm{a}$ & $21,32 \mathrm{a}$ & $18,59 \mathrm{~b}$ & 1,27 & 4,93 \\
\hline & DAP & & & & \\
\hline & \multicolumn{4}{|c|}{$\mathrm{cm}$} & \\
\hline 42 & $13,75 \mathrm{a}$ & $13,38 \mathrm{a}$ & $12,26 \mathrm{~b}$ & 0,89 & 5,37 \\
\hline 45 & $14,28 \mathrm{a}$ & $13,92 \mathrm{ab}$ & $13,06 \mathrm{~b}$ & 0,88 & 5,05 \\
\hline 50 & $14,71 \mathrm{a}$ & $14,28 \mathrm{a}$ & $13,63 \mathrm{a}$ & 1,21 & 6,73 \\
\hline 53 & $14,97 \mathrm{a}$ & $14,61 \mathrm{a}$ & $14,20 \mathrm{a}$ & 0,97 & 5,23 \\
\hline
\end{tabular}

Médias seguidas de letras minúsculas diferentes nas linhas diferem estatisticamente entre si a $5 \%$ de significância pelo teste de Tukey. Em que: MAP - mês após o plantio; MIC - sistema de irrigação via microaspersão; GOT - sistema de irrigação via gotejamento; SI - sem irrigação; DMS - diferença mínima significativa; CV - coeficiente de variação.

Figura 2 - Incrementos corrente (IC) e médio (IM) para diâmetro altura do peito nos sistemas MIC, GOT e SI.

Figure 2 - Increments current (IC) and average (IM) for breast height diameter in systems MIC, GOT and SI.
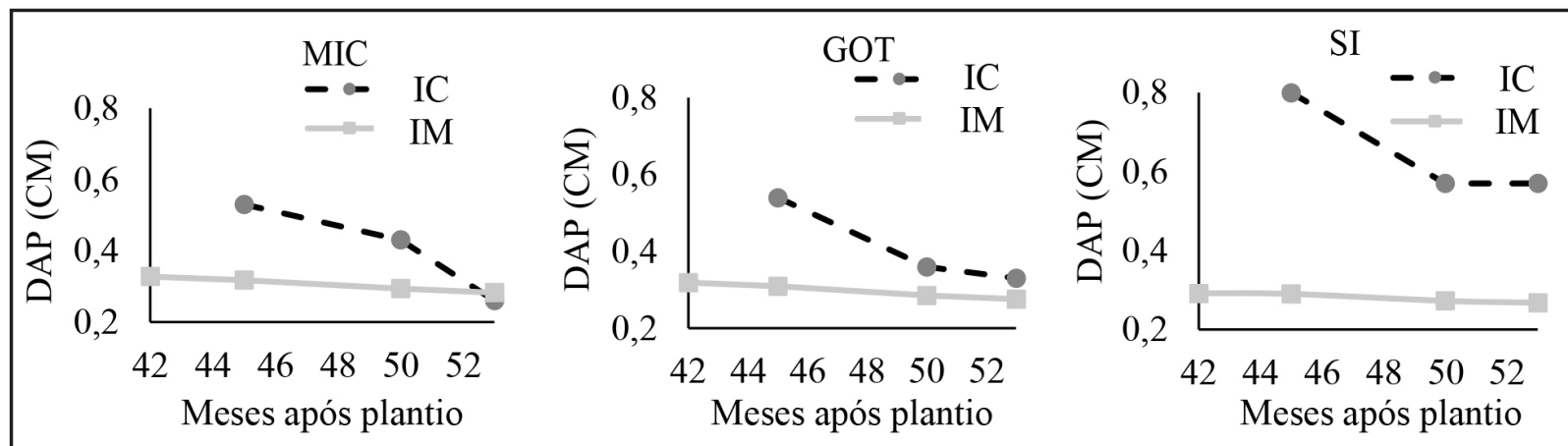

Fonte: Autores (2019)

Source: Authors (2019) 
Figura 3 - Incrementos corrente (IC) e médio (IM) para altura de plantas nos sistemas MIC, GOT e SI.

Figure 3 - Current (IC) and average Increments (IM) for plant height in systems MIC, GOT and SI.

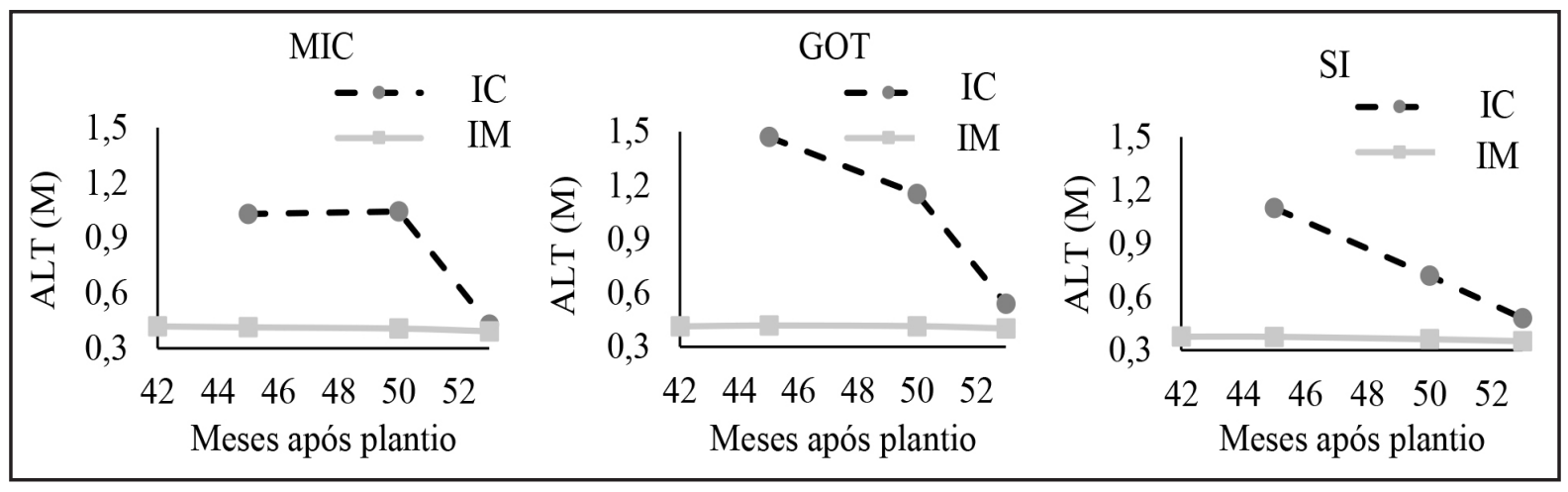

Fonte: Autores (2019)

Source: Authors (2019)

Figura 4 - Incrementos corrente (IC) e médio (IM) para volume de madeira nos sistemas MIC, GOT e SI.

Figure 4 - Current (IC) and average increments (IM) for wood volume in MIC systems, GOT and SI.

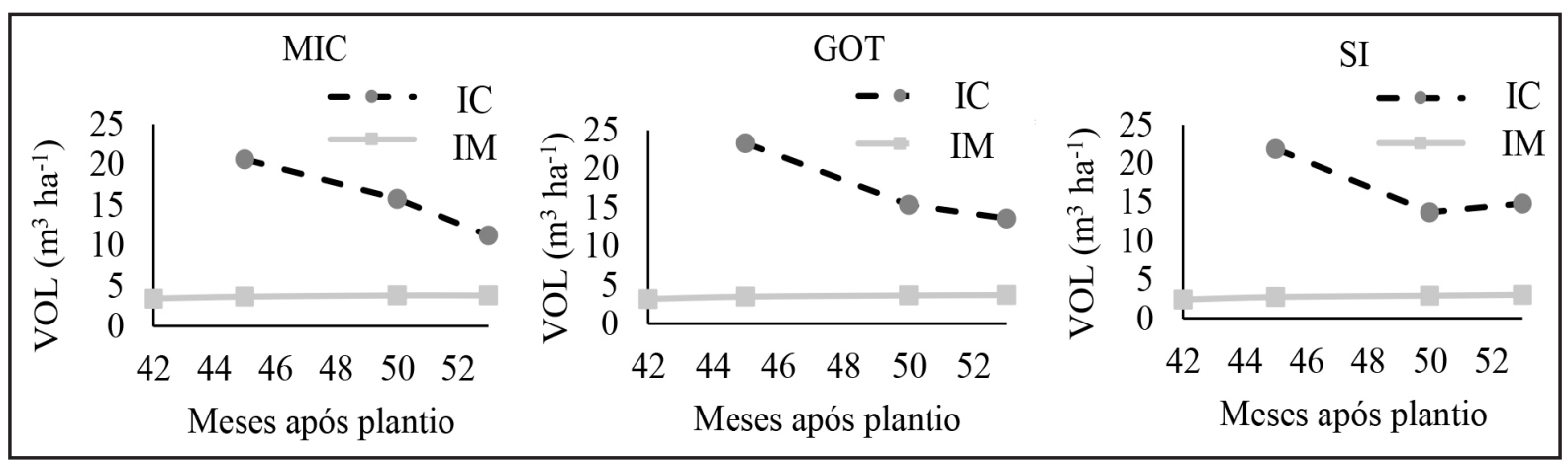

Fonte: Autores (2019)

Source: Authors (2019)

Em relação ao volume de madeira, a irrigação localizada promove maior proximidade ao cruzamento dos índices, quando comparado à área sem irrigação (Figura 4). Esse com portamento é reflexo do maior crescimento em volume nas áreas irrigadas quando comparada às áreas sem irrigação.

O volume de madeira nos sistemas de microaspersão e gotejamento não diferiram entre si e diferiram estatisticamente da área sem irrigação. O sistema de microaspersão e gotejamento proporcionaram um volume de madeira de, respectivamente, $204,42 \mathrm{~m}^{3} \mathrm{ha}^{-1} \mathrm{e}$ $199,35 \mathrm{~m}^{3} \mathrm{ha}^{-1}$, no $53^{\circ}$ MAP (4 anos e 5 meses), enquanto que na área sem irrigação foi de $164,05 \mathrm{~m}^{3} \mathrm{ha}^{-1}$, sendo $19,8 \%$ inferior ao sistema de microaspersão e $17,7 \%$ inferior ao sistema de gotejamento (Tabela 3 ). 


\section{Tabela 3 - Comparação de médias entre os sistemas de irrigação utilizados no cultivo do híbrido de eucalipto Grancam para o volume de madeira (VOL), em Aquidauana-MS.}

Table 3 - Comparison of average between irrigation systems used in grow of hybrid eucalyptus Grancam for wood volume (VOL) in Aquidauana, MS state.

\begin{tabular}{|c|c|c|c|c|c|}
\hline \multirow{3}{*}{ MAP } & \multicolumn{3}{|c|}{ Tratamentos (VOL) } & \multirow[b]{2}{*}{ DMS } & \multirow[b]{2}{*}{$\mathrm{CV}$} \\
\hline & MIC & GOT & SI & & \\
\hline & \multicolumn{3}{|c|}{$\mathbf{m}^{3} \mathbf{h a}^{-1}$} & $\mathrm{~m}^{3} \mathrm{ha}^{-1}$ & $\%$ \\
\hline 42 & $146,20 \mathrm{a}$ & $136,66 \mathrm{a}$ & $104,32 \mathrm{~b}$ & 26,26 & 16,01 \\
\hline 45 & $166,83 \mathrm{a}$ & $159,97 \mathrm{a}$ & $126,22 \mathrm{~b}$ & 26,50 & 13,81 \\
\hline 50 & $193,18 \mathrm{a}$ & $185,70 \mathrm{a}$ & $149,16 \mathrm{~b}$ & 35,40 & 15,83 \\
\hline 53 & $204,42 \mathrm{a}$ & $199,35 \mathrm{a}$ & $164,05 \mathrm{~b}$ & 30,48 & 12,68 \\
\hline
\end{tabular}

Médias seguidas de letras minúsculas diferentes nas linhas diferem estatisticamente entre si a 5\% de significância, pelo teste de Tukey. Em que: MAP - mês após o plantio; MIC - sistema de irrigação via microaspersão; GOT - sistema de irrigação via gotejamento; SI - sem irrigação; DMS - diferença mínima significativa; CV - coeficiente de variação.

Nesse sentido, compreende-se que a irrigação localizada propiciou ganho significativo de produtividade, visto que clones de eucalipto sob irrigação possuem maior taxa de fotossíntese, transpiração e condutância estomática, o que resulta em maior produção de madeira (FERNANDES; CAIRO; NOVAES, 2015).

Alguns autores também constataram a influência da irrigação no volume de madeira. Segundo Reis et al. (2006), avaliando o crescimento de híbridos de eucalipto (Eucalyptus grandis x Eucalyptus urophylla e Eucalyptus camaldulensis x Eucalyptus spp.) submetidos à irrigação no campo, constataram que o volume de madeira foi superior nos tratamentos irrigados, quando comparado aos tratamentos não irrigados.

Portanto, o uso de irrigação em florestas de eucalipto proporciona aumento de volume de madeira em um menor tempo, mesmo em anos com elevado índice pluviométrico, visto que, esta diferença pode ser maior em anos de seca prolongada.

Fernandes, Thaila e Faria (2012) avaliando os efeitos da irrigação e da nutrição mineral no crescimento e produção de Eucalyptus grandis nos cincos anos inicias em Uberaba-MG, com precipitação média anual de $1474 \mathrm{~mm}$, observaram que as áreas irrigadas proporcionaram aumento de $11 \%$ no volume de madeira, produzindo $376,1 \mathrm{~m}^{3} \mathrm{ha}^{-1}$ ano-1 em áreas adubadas e irrigadas e $334,9 \mathrm{~m}^{3} \mathrm{ha}^{-1}$ ano $^{-1} \mathrm{em}$ áreas adubadas e não irrigadas, no quinto ano após implantação.

Assim, visto que a irrigação potencializa a produção de madeira, consequentemente os valores de incremento médio anual (IMA) refletem o mesmo comportamento, haja vista que são informações correlacionadas.

Nesse contexto, sabe-se que os plantios florestais comerciais de eucalipto no Brasil apresentam médias de IMA de $40,7 \mathrm{~m}^{3}$ ha $^{-1}$ ano $^{-1}$ (ASSOCIAÇÃO BRASILEIRA DE PRODUTORES DE FLORESTAS PLANTADAS, 2013). No presente estudo, o IMA foi de $46,35 \mathrm{~m}^{3} \mathrm{ha}^{-1}$ ano $^{-1}$ para sistema de microaspersão, 45,2 $\mathrm{m}^{3} \mathrm{ha}^{-1}$ ano $^{-1}$ para gotejamento e $37,2 \mathrm{~m}^{3}$ ha $^{-1}$ ano $^{-1}$ para área sem irrigação. Superioridade de $12,2 \%$ para microaspersão e $10 \%$ para gotejamento em relação à média nacional. Houve também aumento de $20 \%$ para microaspersão e $17 \%$ gotejamento nas médias de IMA das plantas de eucalipto quando comparada à área sem irrigação.

Corroborando o observado por White et al. (2016) na região da Tasmânia, com precipitação média anual de $515 \mathrm{~mm}$, a utilização da irrigação em espécies de Eucalyptus globulus e Eucalyptus 
nitens promoveu maior condutância estomática das espécies e aumentou em cerca de $37 \%$ os valores médios de IMA para o volume de madeira, no $60^{\circ}$ mês após plantio, quando comparada à área sem irrigação.

Contudo, em meio a um cenário mundial da utilização dos recursos hídricos de forma consciente, analisar a eficiência do uso da água em florestas irrigadas é muito importante.

Observa-se que o uso do sistema de irrigação via gotejamento, proporcionou às plantas do eucalipto Grancam maior eficiência do uso da água na produção volumétrica de madeira, quando comparado à área sem irrigação e ao sistema de microaspersão (Tabela 4).

Tabela 4 - Estimativa da relação de lâmina total de água (LT) (abril/2011 a setembro/2015) com volume de madeira $\left(53^{\circ} \mathrm{MAP}\right)$, para os sistemas MIC, GOT e SI, no cultivo do híbrido de eucalipto Grancam em Aquidauana-MS.

Table 4 - Estimated total water depth ratio (LT) (April / 2011 to September / 2015) with wood volume $\left(53^{\circ} \mathrm{MAP}\right)$ for the MIC systems, GOT and SI, cultivation the hybrid eucalyptus Grancam in Aquidauana, MS state.

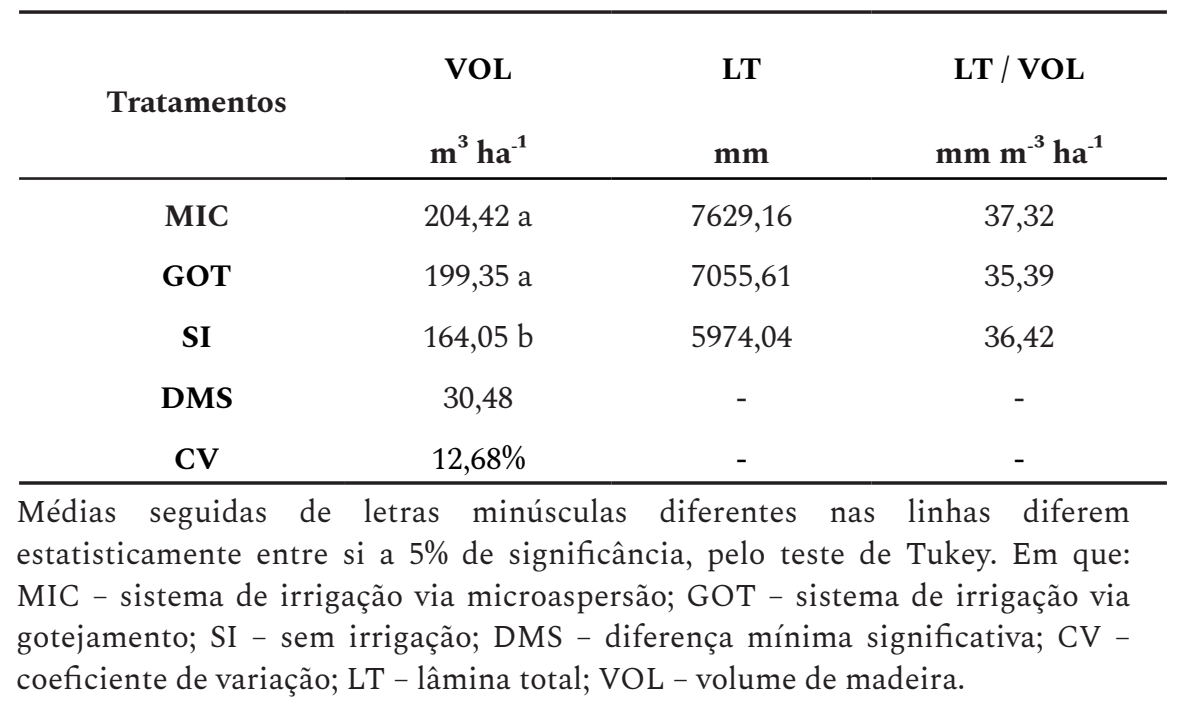

Constata-se que, para o sistema de irrigação por gotejamento, as plantas de eucalipto necessitaram de uma lâmina total de $35,39 \mathrm{~mm} \mathrm{~m}^{-3} \mathrm{ha}^{-1}$ para produzir $1 \mathrm{~m}^{3}$ de volume de madeira, enquanto a área sem irrigação necessitou de $36,42 \mathrm{~mm} \mathrm{~m}^{-3}$ ha $^{-1}$ e a microaspersão $37,32 \mathrm{~mm} \mathrm{~m}^{-3}$ ha $^{-1}$ (Tabela 4).

Nessa mesma linha de raciocínio, White et al. (2016) observaram que as plantas de Eucalyptus globulus e Eucalyptus nitens, irrigadas, necessitaram de menos água para produzir 1 $\mathrm{m}^{3}$ de madeira quando comparadas às plantas não irrigadas. Esse comportamento é de grande importância, pois demonstra que irrigar florestas via gotejamento aumenta a eficiência na utilização dos recursos hídricos, e maximiza a produção de madeira, contribuindo diretamente com a diminuição da pressão em florestas nativas.

Em relação à adubação, quando aliada à irrigação localizada (microaspersão e gotejamento), resultou em maiores médias de altura de plantas, quando comparadas às áreas não irrigadas (Tabela 5).

A fertirrigação (FERT) e a adubação convencional (ADUB) não diferiram estatisticamente entre si, mas diferiram-se da adubação convencional na área sem irrigação (AD-SI). As plantas submetidas à fertirrigação e adubação convencional cresceram, respectivamente, $12,5 \%$ e $11 \%$ a mais que a adubação convencional sem irrigação (Tabela 5). 
Nesse sentido, aliar a irrigação com adubação (FERT e ADUB) potencializa a condução dos nutrientes para raízes das plantas, quando comparada à adubação sem irrigação (AD-SI), pois, se o conteúdo de água de um solo decresce, sua condutividade hidráulica também diminui (TAIZ; ZEIGER, 2009), resultando assim na minimização da acessibilidade das plantas aos nutrientes presentes no solo.

Tabela 5 - Comparação de médias entre adubações utilizadas em cultivo do híbrido de eucalipto Grancam para os atributos altura de plantas (ALT), diâmetro à altura do peito (DAP), volume de madeira (VOL) em Aquidauana-MS.

TABLE 5 - Comparison of means between fertilizations used in grow of hybrid eucalyptus Grancam for the attributes plant height (ALT), diameter at breast height (DAP), wood volume (VOL) in Aquidauana, MS state.

\begin{tabular}{|c|c|c|c|c|c|}
\hline MAP & FERT & ADUB & AD-SI & DMS & CV (\%) \\
\hline & ALT & & & & \\
\hline & & $\mathrm{m}$ & & & \\
\hline 42 & $17,41 \mathrm{a}$ & $17,59 \mathrm{a}$ & $15,81 \mathrm{~b}$ & 1,54 & 7,19 \\
\hline 45 & $18,79 \mathrm{a}$ & 18,71 a & $16,91 \mathrm{~b}$ & 1,56 & 6,81 \\
\hline 50 & 20,69 a & 20,46 a & $18,11 \mathrm{~b}$ & 1,55 & 6,21 \\
\hline \multirow[t]{3}{*}{53} & $21,25 \mathrm{a}$ & 20,88 a & $18,59 \mathrm{~b}$ & 1,27 & 4,93 \\
\hline & DAP & & & & \\
\hline & \multicolumn{4}{|c|}{$\mathrm{cm}$} & \\
\hline 42 & $13,59 \mathrm{a}$ & $13,54 \mathrm{a}$ & $12,26 \mathrm{~b}$ & 0,89 & 5,37 \\
\hline 45 & $14,02 \mathrm{a}$ & $14,18 \mathrm{a}$ & $13,05 \mathrm{~b}$ & 0,88 & 5,05 \\
\hline 50 & $14,56 \mathrm{a}$ & $14,43 \mathrm{a}$ & $13,63 \mathrm{a}$ & 1,21 & 6,73 \\
\hline \multirow[t]{3}{*}{53} & $14,72 \mathrm{a}$ & $14,86 \mathrm{a}$ & $14,20 \mathrm{a}$ & 0,97 & 5,23 \\
\hline & \multicolumn{4}{|l|}{ VOL } & \\
\hline & \multicolumn{4}{|c|}{$\mathrm{m}^{3} \mathrm{ha}^{-1}$} & \\
\hline 42 & $140,72 \mathrm{a}$ & $142,14 \mathrm{a}$ & $104,32 \mathrm{~b}$ & 26,26 & 16,01 \\
\hline 45 & $160,77 \mathrm{a}$ & $166,02 \mathrm{a}$ & $126,22 \mathrm{~b}$ & 26,50 & 13,81 \\
\hline 50 & $191,71 \mathrm{a}$ & $187,14 \mathrm{a}$ & $149,16 \mathrm{~b}$ & 35,40 & 15,83 \\
\hline 53 & $201,44 \mathrm{a}$ & $202,29 \mathrm{a}$ & $164,05 \mathrm{~b}$ & 30,48 & 12,68 \\
\hline
\end{tabular}

Médias seguidas de letras minúsculas diferentes nas linhas diferem estatisticamente entre si a 5\% de probabilidade. Em que: MAP - mês após o plantio; FERT - adubação através de fertirrigação; ADUB - adubação convencional; AD-SI - adubação convencional na área sem irrigação; DMS - diferença mínima significativa; CV coeficiente de variação.

Em relação ao DAP, as adubações realizadas em sistemas irrigados, propiciaram maiores taxas de crescimento mensais até o $45^{\circ} \mathrm{MAP}$, mas não se diferiram estatisticamente da adubação convencional na área sem irrigação, nos últimos períodos avaliados $\left(50^{\circ}\right.$ e $\left.53^{\circ} \mathrm{MAP}\right)$ (Tabela 5). Possivelmente influenciado pelo aumento das chuvas na região, o que possibilitou às plantas da 
AD-SI aumentar o crescimento em DAP, visto, que, plantas não irrigadas exploram um maior volume solo, quando comparadas às submetidas à irrigação.

Neste contexto, alguns autores evidenciam esse comportamento. Segundo Lopes et al. (2014), as raízes da pupunheira possuem melhor distribuição na ausência de irrigação. Corroborando Covre et al. (2015), que observaram que as plantas de Coffea canephora não irrigadas apresentam maiores comprimentos e volume de raízes, por volume de solo, quando comparadas às plantas irrigadas. Resultando em maior comprimento total e frequência total das raízes em áreas não irrigadas, quando comparadas às áreas irrigadas (MORONI; WORLEDGE; BEADLE, 2003). Assim, observa-se que na ausência de irrigação a planta estimula o desenvolvimento de raízes, para aumentar a cobertura de solo em busca por água.

Mas, em contrapartida, a irrigação pode promover o crescimento das raízes finas em Eucalyptus, importantes para absorção de nutrientes. Nesse sentido, Thongo M'bou et al. (2008) observaram que o alongamento de raízes finas de Eucalyptus está relacionado com a sazonalidade das chuvas, em que as maiores taxas de alongamento das raízes finas ocorreram durante a estação chuvosa, quando comparada à estação de seca. Possivelmente esse comportamento está relacionado ao aumento da disponibilidade hídrica.

Em relação ao volume de madeira, a fertirrigação não diferiu estatisticamente da adubação convencional, mas ambas diferiram de adubação convencional sem irrigação. Os maiores valores de crescimentos foram nas áreas submetidas à irrigação localizada, 202,29 $\mathrm{m}^{3} \mathrm{ha}^{-1}$ para adubação convencional e 201,44 $\mathrm{m}^{3} \mathrm{ha}^{-1}$ para fertirrigação em relação à adubação convencional sem irrigação que foi de $164,05 \mathrm{~m}^{3} \mathrm{ha}^{-1}$. Observa-se que a adubação convencional e a fertirrigação foram, respectivamente, $18,9 \%$ e $18,6 \%$ superiores à adubação convencional na área sem irrigação (Tabela 5). Esse resultado evidencia a boa resposta do eucalipto Grancam à adubação.

Portanto, a adubação e a manutenção dos resíduos em um povoamento florestal elevam os teores de nutrientes disponíveis no solo (PAES et al., 2013). Aliar a adubação com irrigação aumenta a eficiência no transporte dos nutrientes às raízes das plantas (TAIZ; ZEIGER, 2009), uma vez que o manejo da água e fertilizantes afeta na distribuição dos nutrientes do solo (SANTOS; FAGERIA; ZIMMERMANN, 2002) e, ainda, na sua disponibilidade às plantas, resultando em maior produtividade para áreas irrigadas quando comparadas às áreas sem irrigação.

Alguns autores como Minhas et al. (2015), observaram esse comportamento em um povoamento de Eucalyptus tereticornis, ao avaliar por 10 anos o efeito da irrigação com águas residuais sobre a produtividade e eficiência no uso da água, e constataram que a irrigação com esgoto promove aumento do volume de madeira, e da eficiência do uso da água, quando comparada à irrigação com a água superficial.

Em relação ao incremento médio anual, a irrigação promoveu maiores valores para as áreas irrigadas, $45,9 \mathrm{~m}^{3}$ ha $^{-1}$ ano $\mathrm{o}^{-1}$ para adubação convencional, $45,7 \mathrm{~m}^{3}$ ha $^{-1}$ ano $^{-1}$ para fertirrigação e $37,2 \mathrm{~m}^{3}$ ha $^{-1}$ ano $^{-1}$ para adubação convencional na área sem irrigação. Em relação à média nacional de 40,7 $\mathrm{m}^{3}$ ha $^{-1}$ ano $^{-1}$ (ASSOCIAÇÃO BRASILEIRA DE PRODUTORES DE FLORESTAS PLANTADAS, 2013), a adubação convencional e a fertirrigação foram 11,3\% e 10,9\% superiores, respectivamente.

Assim, observa-se que aliar a adubação, tanto convencional quanto a fertirrigação, com a irrigação localizada, resulta em maiores incrementos para volume de madeira quando comparada às áreas sem irrigação. Madeira, Araujo e Pereira (1995) salientam que o acúmulo de massa na camada de serapilheira e a liberação de nutrientes pela mesma camada, é fortemente aumentada, quando se disponibiliza simultaneamente água e nutrientes.

Aslam et al. (2015) atribuem esse resultado ao uso da irrigação, visto que esta tecnologia proporcionou aumento da disponibilidade de nutrientes para as plantas adubadas, ou seja, insumos artificiais podem substituir o papel de biota do solo e aliado à irrigação promovem melhores resultados.

Evidencia-se assim, que a fertirrigação pode ser substituída pela adubação convencional em florestas irrigadas, haja vista que ela minimiza custos com mão de obra, desperdício de 
fertilizantes, possibilita a distribuição de nutrientes de acordo com a necessidade da cultura (OLIVEIRA et al., 2011), e produz mais biomassa (PEGORARO et al., 2013).

\section{Conclusões}

No $53^{\circ}$ mês após plantio o híbrido Grancam apresenta crescimento em altura para plantas irrigadas por gotejamento de $13 \%$ e por microaspersão de $11 \%$ a mais em relação às plantas não irrigadas.

A irrigação localizada (microaspersão e gotejamento) aumenta a produção volumétrica de madeira para o híbrido Grancam, além disso, quando se utilizada o sistema de gotejamento há aumento da eficiência do uso da água na produção volumétrica de madeira.

A fertirrigação, tanto no sistema de microaspersão quanto de gotejamento, pode substituir a adubação convencional em florestas irrigadas, pois esta técnica aumenta a eficiência do uso de nutrientes pela planta, devido à aplicação dos mesmos com água de maneira pontual e próximo às raízes, evitando dosagens excessivas de fertilizantes.

\section{Agradecimentos}

Agradecemos a Fundação Coordenação de Aperfeiçoamento de Pessoal de Nível Superior (CAPES), pela concessão da bolsa de mestrado para realização deste trabalho.

\section{Referências}

ALLEN, R. G. et al. Crop evapotranspiration: guidelines for computing crop requirements. Roma: FAO, 1998. 301 p.

ALVES, M. E. B. et al. Estimate of the crop coefficient for Eucalyptus cultivated under irrigation during initial growth. Cerne, Lavras, v. 19, p. 247-253, 2013.

ANDRADE, L. R. M. Corretivos e fertilizantes para culturas perenes e semiperenes. In: SOUSA, D. M. G.; LOBATO, R. (ed.). Cerrado: correção do solo e adubação. 2. ed. Brasília: EMBRAPA Informação Tecnológica, 2004. p. 317-366.

ASLAM T. J. et al. Impacts of eucalypt plantation management on soil faunal communities and nutrient bioavailability: trading function for dependence. Biology Fertility Soils, Berlin, v. 51, p. 637-644, 2015.

ASSOCIAÇÃO BRASILEIRA DE PRODUTORES DE FLORESTAS PLANTADAS. Anuário estatístico ABRAF 2013 ano base 2012. Brasília: ABRAF, 2013. 148 p.

BERnARDo, S.; SOARES, A. A.; MANTOVANI, E. C. Manual de irrigação. 8. ed. Viçosa, MG: UFV, 2006. 625 p.

BORGES, A. L. et al. Fertirrigação da bananeira. Cruz das Almas: EMBRAPA, 2006. (Circular Técnica, 84).

CONSELHO DE INFORMAÇÕES SOBRE BIOTECNOLOGIA. Guia do Eucalipto oportunidades para um desenvolvimento sustentável. [S. l.: s. n.], 2008. 19 p.

COVRE, A. M. et al. Distribuição do sistema radicular de cafeeiro conilon irrigado e não irrigado. Pesquisa Agropecuária Brasileira, Brasília, v. 50, n. 11, p. 1006-1016, 2015.

DOMBROSKI, J. L. D. et al. Ecophysiology of water stressed Handroanthus impetiginosus (Mart. Ex. DC Mattos) Seedlings. Scientia Forestalis, Piracicaba, v. 42, p. 155, 2014.

FERNANDES, A. L. T.; THAILA, M. F.; FARIA, M. F. Análise biométrica de florestas irrigadas 
de eucalipto nos cinco anos iniciais de desenvolvimento. Revista Brasileira de Engenharia Agrícola e Ambiental, Campina Grande, v. 16, n. 5, p. 505-513, 2012.

FERNANDES, E. T.; CAIRO, P. A. R.; NOVAES, A. B. Respostas fisiológicas de clones de eucalipto cultivados em casa de vegetação sob deficiência hídrica. Ciência Rural, Santa Maria, v. 45 , n. 1, p. 29, 2015.

FONSECA, S. M. et al. Manual prático de melhoramento genético do eucalipto. Viçosa: UFV, 2010. 200 p.

FREITAS, P. C. et al. Efeito da disponibilidade hídrica e da aplicação de potássio e sódio nas características anatômicas do lenho juvenil de Eucalyptus grandis. Revista Árvore, Viçosa, MG, v. 39, n. 2, p. 405-416, 2015.

GONÇALVES, J. L. M. et al. Assessing the effects of early silvicultural management on longterm site productivity of fast-growing eucalypt plantations: the Brazilian experience. Southern Forests, South África, v. 70, n. 2, p. 105-118, 2008.

INDÚSTRIA BRASILEIRA DE ÁRVORES. Relatório IBÁ 2014. Brasília: Pöyry, 2014. 100 p.

INDÚSTRIA BRASILEIRA DE ÁRVORES. Relatório IBÁ 2015. Brasília: Pöyry, 2015. 80 p.

LOPES, J. L. W. et al. Nutrição mineral de mudas de eucalipto produzidas sob diferentes lâminas de irrigação e substratos. Revista Brasileira de Ciência do Solo, Viçosa, MG, v. 31, n. 4, p. 713$722,2007$.

LOPES, A. S. et al. Distribution of the root system of peach palm under drip irrigation. Acta Scientiarum Agronomy, Maringá, v. 36, n. 3, p. 317-321, 2014.

MADEIRA, M.; ARAUJO, M. C.; PEREIRA, J. S. Effect of water and nutrient supply on amount and on nutrient concentration of litterfall and forest floor litter in Eucalyptus globulus plantations. Plant and Soil, The Hague, v. 168, p. 287-295, 1995.

MAROUELLI, W. A.; SILVA, H. R.; SILVA, W. L. C. Irrigação do tomateiro para processamento. Brasília: EMBRAPA Hortaliças, 2012. 22 p. (Circular Técnica ,102).

MINHAS P. S. et al. Effect of long-term irrigation with wastewater on growth, biomass production and water use by Eucalyptus (Eucalyptus tereticornis $\mathrm{Sm}$.) planted at variable stocking density. Agricultural Water Management, Amsterdam, v. 152, p. 151-160, 2015.

MORONI, M. T.; WORLEDGE, D.; BEADLE, C. L. Root distribution of Eucalyptus nitens and Eucalyptus globulus in irrigated and droughted soil. Forest Ecology and Management, Amsterdam, v. 177, p. 399-407, 2003.

OLIVEIRA, F. A. et al. Calibração de extratores providos de cápsula porosa para monitoramento da salinidade e da concentração de íons. Engenharia Agrícola, Jaboticabal, v. 31, n. 3, p. 520-528, 2011.

OLIVEIRA NETO, S. N. et al. Crescimento e distribuição diamétrica de Eucalyptus camaldulensis em diferentes espaçamentos e níveis de adubação na região de Cerrado de Minas Gerais. Revista Floresta, Curitiba, v. 40, n. 4, p. 755-762, 2010.

PACHECO, A. et al. In-ground irrigation and fertirrigation irrigation system in the hybrid eucalyptus grancam. Journal of Agronomy, Pakistan, v. 15, p. 76-82, 2016.

PAES, F. A. S. V. et al. Impacto do manejo dos resíduos da colheita, do preparo do solo e da adubação na produtividade de eucalipto. Revista Brasileira de Ciência do Solo, Viçosa, MG, v. 37, p. 1081-1090, 2013.

PAULA, R. R. et al. Propriedades edáficas e desenvolvimento de eucalipto em topossequência na flona Mário Xavier-RJ. Floresta e Ambiente, Rio de Janeiro, v. 19, n. 3, p. 344-351, 2012.

PEGORARO, R. F. et al. Fenóis derivados da lignina, carboidratos e amino açúcares em 
serapilheira e solos cultivados com eucalipto em sistemas convencional e fertirrigado. Revista Árvore, Viçosa, MG, v. 37, n. 3, p. 519-529, 2013.

PEREIRA, J. C. D. et al. Características da madeira de algumas espécies de eucalipto plantadas no Brasil. Colombo: EMBRAPA Florestas, 2000. 113 p. (Documentos, 38).

REIS, G. G. et al. Crescimento de raízes e da parte aérea de clones de híbridos de Eucalyptus grandis x Eucalyptus urophylla e de Eucalyptus camaldulensis x Eucalyptus spp. submetidos a dois regimes de irrigação no campo. Revista Árvore, Viçosa, MG, v. 30, n. 6, p. 921-931, 2006.

RODRIGUES, L. C. E. Gerenciamento da produção florestal. Piracicaba: Universidade de São Paulo, Escola Superior de Agricultura Luiz de Queiroz, Departamento de Ciências Florestais, 1991. v. 13 (Documentos Florestais).

RÖTZER, T. et al. Tree species and size drive water consumption of beech/spruce forests - a simulation study highlighting growth under water limitation. Plant Soil, Dordrecht, v. 418, n. 5, p. 1-20, 2017.

SANTOS, A. B.; FAGERIA, N. K.; ZIMMERMANN, F. J. P. Atributos químicos do solo afetado pelo manejo da água e do fertilizante potássico na cultura de arroz irrigado. Revista Brasileira de Engenharia Agrícola e Ambiental, Campina Grande, v. 6, n. 1, p. 12-16, 2002.

SCHIAVO, J. A. et al. Caracterização e classificação de solos desenvolvidos de arenitos da formação Aquidauana-MS. Revista Brasileira de Ciência do Solo, Viçosa, MG, v. 34, p. 881-889, 2010.

SOUZA, C. R. et al. Comportamento da Acacia mangium e de clones de Eucalyptus grandis x Eucalyptus urophylla em plantios experimentais na Amazônia Central. Scientia Forestalis, Piracicaba, n. 65, p. 95-101, 2004.

SOUZA, M. J. H. et al. Disponibilidade hídrica do solo e produtividade do eucalipto em três regiões da Bacia do Rio Doce. Revista Árvore, Viçosa, MG, v. 30, n. 3, p. 399-410, 2006.

TAIZ, L.; ZEIGER, E. Fisiologia Vegetal. 4. ed. Porto Alegre: Artmed, 2009. 848 p.

THONGO M'BOU, A. et al. Root elongation in tropical Eucalyptus plantations: effect of soil water content. Annals of Forest Science, French, v. 65, p. 609, 2008.

VALADARES, J.; PAULA, N. F.; PAULA, R. C. Physiological changes in Eucalyptus hybrids under different irrigation regimes. Revista Ciências Agronômica, Fortaleza, v. 45, n. 4, p. 805-814, 2014.

VILAS BÔAS, O.; MAX, J. C. M.; MELO, A. C. G. Crescimento comparativo de espécies de Eucalyptus e Corymbia no município de Marília, SP. Revista do Instituto Florestal, São Paulo, v. 21, p. 63-72, 2009.

WHITE, D. et al. Wood production per evapotranspiration was increased by irrigation in plantations of Eucalyptus globulus and Eucalyptus nitens. New Forests, Dordrecht, v. 47, p. 303, 2016. 